\title{
Eating with Familiar Friends Decreases the Electrical Taste Threshold
}

\author{
Shiho Tsuchida", Genki Sakauchi',2, Momoko Asada', Naoto Sato', Kasumi Suzuki', \\ Misaki Kaiwa1, Kenichi Shibuya1, Hiromi Inaba ${ }^{*}$ (i) \\ ${ }^{1}$ Department of Health and Nutrition, Niigata University of Health and Welfare, Niigata, Japan \\ ${ }^{2}$ Kaetsu Hospital, Niigata, Japan \\ Email: ^inaba@nuhw.ac.jp
}

How to cite this paper: Tsuchida, S., Sakauchi, G., Asada, M., Sato, N., Suzuki, K., Kaiwa, M., Shibuya, K. and Inaba, H. (2019) Eating with Familiar Friends Decreases the Electrical Taste Threshold. Journal of Behavioral and Brain Science, 9, 154-163.

https://doi.org/10.4236/jbbs.2019.93013

Received: February 27, 2019

Accepted: March 22, 2019

Published: March 25, 2019

Copyright $\odot 2019$ by author(s) and Scientific Research Publishing Inc. This work is licensed under the Creative Commons Attribution International License (CC BY 4.0).

http://creativecommons.org/licenses/by/4.0/

\begin{abstract}
Communal eating reportedly induces changes in food-related behaviors such as increased consumption and alleviation of indefinite complaints. Here, we examined the influence of intimacy with co-eaters on the palatability of the food and the physiological taste thresholds. The study was a single-blind crossover trial with 16 healthy women aged $18-19$ years (two close friends $\times$ 8 ) as participants. We examined the effect of four preset conditions with regard to taste (condition $1=$ tasting alone; condition $2=$ tasting with a friend; condition 3 = tasting with three unfamiliar individuals; condition $4=$ tasting with a friend and two unfamiliar individuals). Electrical taste thresholds were measured pre-and post-eating. The subjective evaluation of taste did not show any significant difference between the four conditions ( $p>0.05)$. However, the electrical taste threshold significantly decreased when eating with close friends $(\mathrm{p}<0.05)$. As a factor associated with the meal environment, co-eating with family or friends appears to influence tastiness; however, in the present study, it showed no effect on the perception of taste. Nevertheless, eating with friends significantly decreased the electrical taste threshold and enhanced the perception of taste. Decrease in the electrical taste threshold was observed only when eating with a close friend; it was not observed when eating with other people and showed no association with the total number of individuals co-eating.
\end{abstract}

\section{Keywords}

Co-Eating, Taste Threshold, Familiar Person, Tastiness, Physiological Changes

\section{Introduction}

Communal dining is one of the most common social activities. Typically, child- 
ren begin to eat with their parent(s) early in childhood. Studies have shown that food tends to taste better when consumed in the company of others than when eaten alone [1]. This phenomenon is termed the "social facilitation of eating" [1], which refers not only to the increase in the volume of food intake but also to the taste [2]. One of the explanations for this phenomenon is associated with the positive effect of co-eating on mood; when people eat together, they usually talk to each other and experience social unity [3]. These positive changes in mood may result in the social facilitation of eating [4] [5]. Studies have shown that people tend to consume more food with friends or family members than with strangers [5] [6]. However, Hirsch and Kramer [7] reported that people did not consume more food in a large unfamiliar group of 50 to 70 people. Thus, eating in a crowd does not affect social facilitation. In addition, the quality of social relationships among the group, particularly when eating with familiar people, is considered to be an important factor for such facilitation. Studies conducted in children have shown that eating in a group results in an increased food intake and inculcates good eating behavior and attitudes toward food [8] [9] [10].

However, no studies have investigated the influence of co-eating on the electrical taste threshold; moreover, the effect of eating with a complete stranger or a person with whom one shares a low level of intimacy on the taste of food has not been clarified. The present study aimed to investigate the influence of eating with a familiar group on the taste of food. The present study enrolled 16 female participants because the taste threshold level in females is known to be lower than that in males [11].

\section{Methods}

\subsection{Participants}

In the present study, 16 healthy female participants (age range, 18 - 19 years; mean height: $161.8 \pm 7.6 \mathrm{~cm}$; mean body weight: $52.1 \pm 7.6 \mathrm{~kg}$ ) were included. All participants were unaware of the aim of the experiment and had normal olfaction and vision. The study protocol has been approved by the Ethics Committee of the Niigata University of Health and Welfare (No. 17647-160307). Each participant provided written informed consent after detailed counseling regarding the methodology of the study.

\subsection{Food for the Preference Survey and Method of Provision}

Before beginning the tasting experiment, participants were informed that their task was to evaluate the taste of different types of food (bread [Chojuku, Shikisima Bread Co. Ltd.], rice cracker [Teshioya, Kameda Co. Ltd.], and gummy candy [Grape and Orange flavors, Meiji Co. Ltd.]) and that they were free to eat as much food as they liked. The bread was cut into pieces of $10 \mathrm{~cm} \times 10 \mathrm{~cm}$ (without the crust of the bread slice). The participants completed a short questionnaire in Japanese regarding their subjective evaluation of each food. Their responses were assessed based on a visual analog scale (VAS; response options ranged from "not at all" to "extremely"). The following questions were included: 
"How do you feel regarding the taste of the food", "How do you feel regarding the intensity of the taste", "How do you feel about the texture of the food", "Do you like the food", and "Would you eat this food again"? In addition, before beginning the survey and consuming the foods, the participants were requested to wash their mouths with ion-exchanged water.

\subsection{Experimental Conditions}

A single-blind crossover studywas conducted at random, and four conditions were set (Figure 1): condition 1: tasting alone; condition 2: tasting with a friend; condition 3: tasting with three unfamiliar individuals; Condition 4: tasting with a friend and two unfamiliar individuals. Conditions 1 and 2 were treated as people-related conditions and conditions 3 and 4 were treated as group-related conditions (Figure 2). Experiments with the four conditions were performed on separate days at intervals of one or more days.

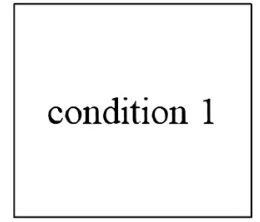

A

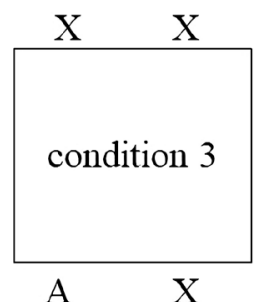

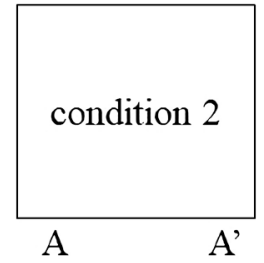

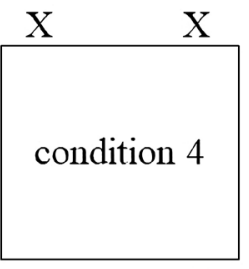

A

$\mathrm{A}^{\prime}$

Figure 1. Four experiment conditions. A indicates the participant; A and A' represent friends; $\mathrm{X}$ indicates a person who is unfamiliar to $\mathrm{A}$.

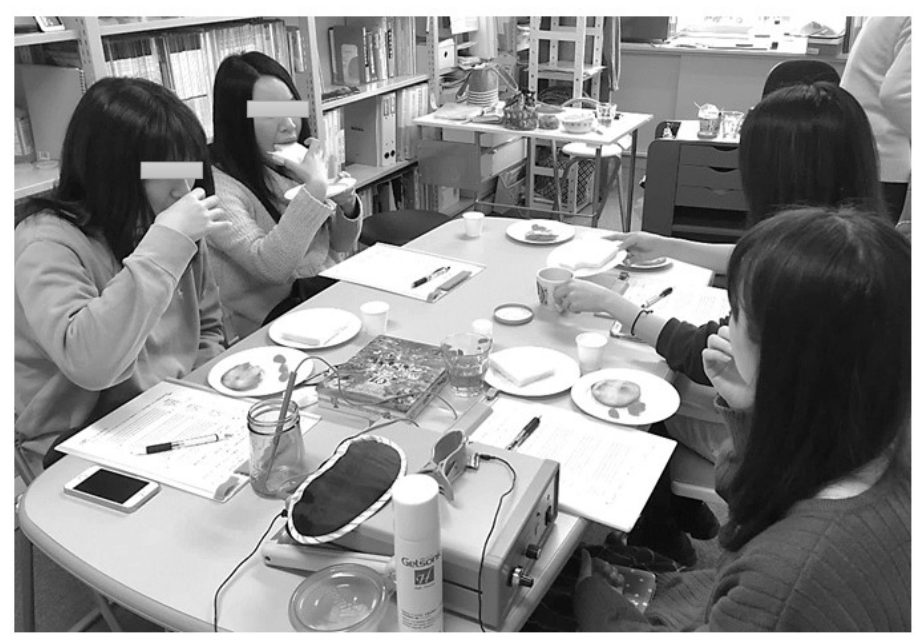

Figure 2. Scene of co-eating with four people. Group condition with a friend (condition 4). 


\subsection{Experimental Procedure}

In the experimental setting, the room temperature was $24.4^{\circ} \mathrm{C} \pm 0.1^{\circ} \mathrm{C}$, and the humidity level was $47.0 \% \pm 0.9 \%$ (mean \pm standard error). Participants were not permitted to consume any food or drink other than water for at least 2 hours before the test and avoided salty food and caffeine-rich drinks (coffee, tea, and green tea) one day prior to the test day. The electrical taste threshold of all participants was tested pre- and post-eating using an electrical stimulator meter (AO-A 41000, Applied Office, Tokyo, Japan). The tongue median groove fungi form papilla (chorda innervation dominant region) was used as the contact point of the electrode (stainless steel, 5-mm diameter). The stimulation time was set to 2 seconds. The electrical flow rate was gradually decreased from $32 \mu \mathrm{A}$ by $2 \mu \mathrm{A}$, and the participants had to indicate when the sensation disappeared rather than when it began. To exclude the influence of visual stimuli, participants wore eye masks during tasting. The taste threshold experiment was conducted before and after eating the foods.

\section{Statistical Analysis}

To analyze the difference between the VAS and taste threshold conditions, we used Bayesian analysis using the MCMCglmm package of R [12], which is designed for fitting generalized linear mixed models; it employs Markov chain Monte Carlo (MCMC) methods that represent a combination of Gibbs sampling. The total number of iterations was 200,000 , and the size of the burn-in part was 30,000 . The effect was significant if the fit of the model that included the relevant term significantly differed from the fit of the model that did not include that term [13]. Accordingly, p-values $<0.05$ were considered to be statistically significant.

\section{Results}

We analyzed the effects of eating with friends on the taste threshold and VAS data pertaining to taste. The results of MCMCglmm are summarized in Table 1. We found significantly lower electrical taste thresholds in the condition of eating with friends than in other conditions ( $p=0.034$; Table 1, Figure 3$)$. An increase in the number of friends by one resulted in a mean decrease in the electrical taste threshold by $7.41 \mu \mathrm{A}$. Furthermore, an increase in the number of people by one resulted in a mean decrease in electrical taste threshold by $1.66 \mu \mathrm{A}$ (Table 1). The number of people eating together tended to change the electrical taste threshold; however, the effect was not statistically significant $(\mathrm{p}=0.066$; Table 1 , Figure 4). A significant difference was observed between the electrical taste threshold pre-and post-eating (pMCMC $=0.047$ [Table 1]; pre: $8.23 \pm 0.97 \mu \mathrm{A}$, post: $10.75 \pm 1.20 \mu \mathrm{A}$ [Figure 5]).

In addition, no significant difference was observed among the four conditions with respect to any of the five items ("taste", "taste intensity", "taste good", "preference", and "appetite"), as assessed by VAS (Table 2). 
Table 1. Results from MCMC generalized liner mixed-effects models to investigate the effect of co-eating to test threshold.

\begin{tabular}{lccc}
\hline \multicolumn{2}{c}{ Effective sample size } & Post mean & $\mathrm{p}$ \\
\hline $\begin{array}{l}\text { Random effects } \\
\text { subjects }\end{array}$ & 9850 & 31.48 & \\
Fixed & & & \\
\multicolumn{1}{l}{ persons } & 9850 & -1.66407 & 0.0653 \\
friends & 9492 & -7.41302 & $0.0343^{\star}$ \\
pre-post & 9850 & -2.51851 & $0.0467^{\star}$ \\
persons:friends & 9850 & 2.69712 & $0.0317^{\star}$ \\
Intercepts & 9344 & 14.6766 & $<1 \times 10^{-0.4 \star}$ \\
\hline
\end{tabular}

$\mathrm{n}=8$ pairs. ${ }^{*}$ : Significant difference at $\mathrm{p}<0.05$.

Table 2. Results of subjective evaluation of physical condition, hungry level and taste in each condition.

\begin{tabular}{cccccr}
\hline \multicolumn{5}{c}{} & \multicolumn{2}{c}{ condition } & & \\
& 1 & 2 & 3 & 4 & \\
\hline physical condition & $3.67 \pm 1.07$ & $4.42 \pm 0.51$ & $4.50 \pm 0.67$ & $3.91 \pm 1.14$ & 0.522 \\
hungry level & $4.42 \pm 1.00$ & $3.92 \pm 1.24$ & $4.17 \pm 0.83$ & $3.82 \pm 1.17$ & 0.335 \\
taste & $58.8 \pm 20.9$ & $64.1 \pm 18.3$ & $57.4 \pm 19.9$ & $65.1 \pm 22.2$ & $>0.05$ \\
taste intensity & $42.8 \pm 23.3$ & $40.4 \pm 22.4$ & $49.1 \pm 22.2$ & $50.1 \pm 23.8$ & $>0.05$ \\
good taste & $63.5 \pm 18.1$ & $64.8 \pm 21.0$ & $57.3 \pm 16.6$ & $63.5 \pm 20.5$ & $>0.05$ \\
liking & $60.9 \pm 22.4$ & $65.1 \pm 23.1$ & $58.9 \pm 21.1$ & $62.0 \pm 23.3$ & $>0.05$ \\
appetite & $57.6 \pm 22.6$ & $63.3 \pm 22.2$ & $57.4 \pm 24.1$ & $59.1 \pm 24.8$ & $>0.05$ \\
\hline
\end{tabular}

Results of a total of 32 experiments with 4 trials $\times 8$ pairs. All taste before survey (pre) and after preference study (post) electric taste threshold value.

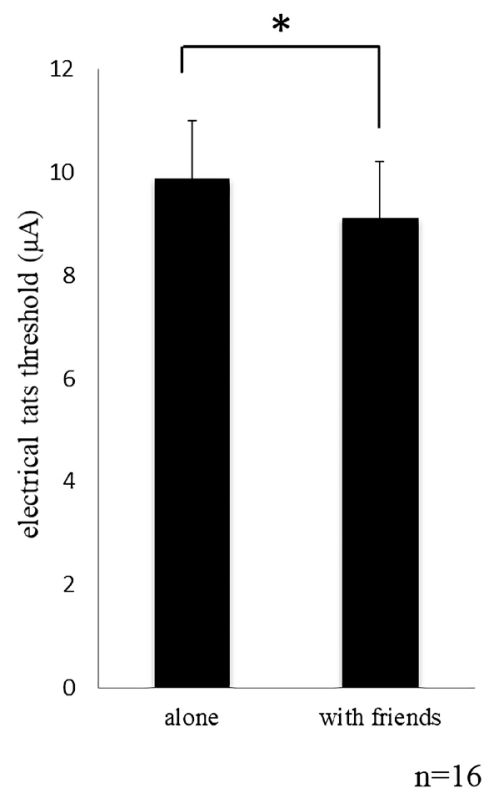

Figure 3. Estimated effect of friend's existence on taste threshold in micro amps $(\mu \mathrm{A})$. Asterisk indicates a significant difference $(\mathrm{p}<0.05)$. 


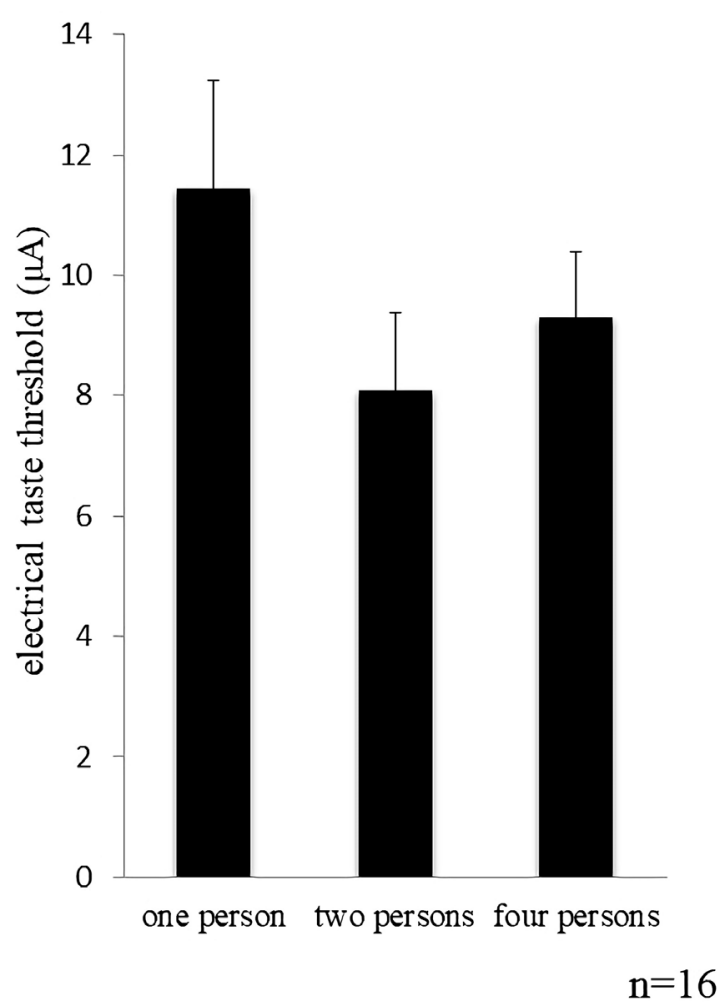

Figure 4. Effect of the number of persons on taste threshold in micro amps $(\mu \mathrm{A})$.

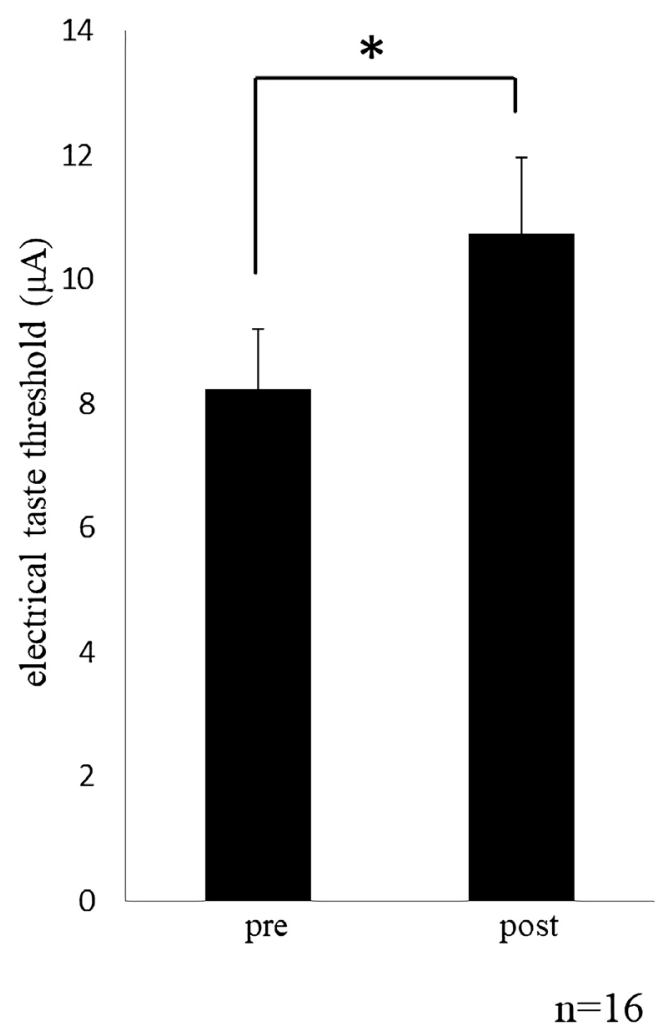

Figure 5. Difference between pre- and post-eating taste threshold in micro amps $(\mu \mathrm{A})$. Asterisk indicates a significant difference $(\mathrm{p}<0.05)$. 


\section{Discussion}

This study aimed to examine the influence of eating food with friends on the taste threshold. The key finding was that the condition of eating with friends enhanced taste sensitivity compared with the condition of eating alone or with unfamiliar individuals. However, no significant difference was observed among the conditions of eating with friends, eating with unfamiliar individuals, and eating alone.

The electrical taste threshold, which is an indicator of physiological change, was significantly decreased when eating food with close friends $(9.89 \pm 1.12 \mu \mathrm{A}$ vs. $9.10 \pm 1.12 \mu \mathrm{A}$; Figure 3, Table 1). Electrical taste threshold measurement involves nonspecific stimulation of taste cells and nerves with a weak electrical quantity and the measurement of nerve fiber excitation [14]. This methodology is used to measure the taste threshold in medical settings for evaluation of taste disorders, and its reliability is reported to be high [15] [16]. In this study, the taste sensations were not limited to five basic tastes.

Several factors may influence the taste threshold such as age, saliva volume, color and odor of food, physical condition, local environment, and emotional factors [17] [18] [19]. In this study, we focused on the effect of four conditions on the emotions. The participants consumed the same bread indifferent meal environments.

Depression was inferred to be lesser when eating with close friends than when eating with strangers. In this study, eating with a close friend (conditions 2 and 4) significantly decreased the electrical taste threshold compared with the condition without friends (conditions 1 and 3). However, one of the factors showed a difference with regard to depression (Table 1).

The taste of food and whether it is "delicious" is determined by its complex physical and chemical properties, including attributes such as temperature and smell. In addition to the sensory elements directly connected to the food, the physical condition of the consumer and external environmental factors majorly influence the taste of food. Furthermore, the perception of taste was reported to be closely associated with parasympathetic nervous activity [20]. Factors such as background music and stress have been reported to be associated, such that back ground music directly influences the biological indicators of stress such as hormone levels (e.g. cortisol), blood pressure, and perceived anxiety.

Compared with eating with strangers, eating with close friends has a parasympathomimetic effect that relieves stress. Thus, eating with friends is considered to decrease the electrical taste threshold and enhance the taste of food. We used conditions 1 - 4 as the model of co-eating (Figure 1). There were no significant differences among the five items (i.e. "tastiness", "taste intensity", "good taste", "liking", and "appetite"), as evaluated using VAS (Table 2). It has been reported that co-eating does not necessarily increase the score of "tastiness".

Kusano-Tsunoh et al. [21] have reported that eating behavior is affected by the presence of other people. Co-eating was shown to increase food intake re- 
gardless of age (social promotion) [22] [23]. However, suppression of food intake when co-eating has been observed, and Herman, Roth, \& Polivy [24] have proposed a model that comprehensively considers food intake.

The electrical taste threshold, which is an indicator of physiological changes, was decreased when eating with close friends $(9.89 \pm 1.12 \mu \mathrm{A}, 9.10 \pm 1.12 \mu \mathrm{A}$; Figure 3, Table 1). Positive emotions may have resulted in a decreased taste threshold. However, VAS measurements did not reflect a change in "tastiness" when co-eating (Table 2). These results suggest that factors other than the biological changes may influence the perception of taste. Further study is required to clarify these differences between the perception of taste and physiological changes.

Changes in food intake (energy content and weight) are objective indicators of eating behavior; however, it is difficult to accurately assess subjective factors such as emotion and the perception of taste. Our findings are consistent with the results of Mierson et al. [14] who reported that co-eating does not necessarily improve the sense of "tastiness".

Several studies conducted in Japan and overseas have documented the effect of co-eating among children at home [25] [26]. Hammons reported that the frequency of shared family meals is significantly related to nutritional health in children. In addition, the children are less likely to engage in unhealthy meals. However, no studies have investigated the influence of co-eating on the electrical taste threshold in adult subjects. In addition, there is no report regarding the influence of interpersonal intimacy on the electrical taste threshold when co-eating. The present study examined the taste threshold under various co-eating conditions. However, considering the association between parental density and taste threshold with people who eat together every day, research on the influence of familiarity on co-eating requires further development. Eating has a formative effect on the development of human nature. Communal eating provides an opportunity for communication, promotes sensibilities, and shapes emotional development. However, it may be difficult to create such meal environments because "individual food" and "eating alone" has become more common. Thus, it is important to consider not only the issue of "eating alone" and "individual food" but also "who to eat with". In addition, further studies may help develop a better meal environment by considering physiological changes in addition to the mental impact of co-eating.

As the limitation of this study, this experiment was conducted in a situation different from the general meal of eating bread for few minutes; therefore, further studies are needed to check whether the same results would be observed while actually eating meal.

In conclusion, when considering "who to eat with" as a factor associated with the meal environment, eating meals with family or close friends appears to influence "tastiness"; however, in this study, no significant effect on "taste" was observed. It was found that eating with friends significantly reduced the electrical taste threshold, which enhanced the perception of "taste". Reduction in elec- 
trical taste threshold was observed only when eating with a close friend; the total number of individuals who were co-eating did not affect the taste threshold.

\section{Conflicts of Interest}

The authors declare no conflicts of interest regarding the publication of this paper.

\section{References}

[1] Bellisle, F. and Dalix, A.M. (2001) Cognitive Restraint Can Be Offset by Distraction, Leading to Increased Meal Intake in Women. The American Journal of Clinical Nutrition, 74, 197-200. https://doi.org/10.1093/ajcn/74.2.197

[2] Herman, C.P. (2015) The Social Facilitation of Eating. A Review. Appetite, 86, 61-73. https://doi.org/10.1016/j.appet.2014.09.016

[3] Baumeister, R.F. and Leary, M.R. (1995) The Need to Belong: Desire for Interpersonal Attachments as a Fundamental Human Motivation. Psychological Bulletin, 117, 497-529. https://doi.org/10.1037/0033-2909.117.3.497

[4] Hetherington, M.M., Anderson, A.S., Norton, G.N.M. and Newson, L. (2006) Situational Effects on Meal Intake: A Comparison of Eating Alone and Eating with Others. Physiology \& Behavior, 88, 498-505. https://doi.org/10.1016/j.physbeh.2006.04.025

[5] Sommer, W., Stürmer, B., Shmuilovich, O., Martin-Loeches, M. and Schacht, A. (2013) How about Lunch? Consequences of the Meal Context on Cognition and Emotion. PLOS ONE, 8, e70314. https://doi.org/10.1371/journal.pone.0070314

[6] Clendenen, V.I., Herman, C.P. and Polivy, J. (1994) Social Facilitation of Eating among Friends and Strangers. Appetite, 23, 1-13. https://doi.org/10.1006/appe.1994.1030

[7] Hirsch, E.S. and Kramer, E.M. (1993) Situational Influences on Food Intake. In: Marriott, B.M., Ed., Nutritional Needs in Hot Environments, National Academy Press, Washington DC, 215-243.

[8] De Castro, J.M. (1991) Social Facilitation of the Spontaneous Meal Size of Humans Occurs on Both Weekdays and Weekends. Physiology \& Behavior, 49, 1289-1291. https://doi.org/10.1016/0031-9384(91)90365-U

[9] Roach, E., Viechnicki, G.B., Retzloff, L.B., Davis-Kean, P., Lumeng, J.C. and Miller, A.L. (2017) Family Food Talk, Child Eating Behavior, and Maternal Feeding Practices. Appetite, 117, 40-50. https://doi.org/10.1016/j.appet.2017.06.001

[10] Salvy, S.J., Howard, M., Read, M. and Mele, E. (2009) The Presence of Friends Increases Food Intake in Youth. The American Journal of Clinical Nutrition, 90, 282-287. https://doi.org/10.3945/ajcn.2009.27658

[11] Coats, A.C. (1974) Effects of Age, Sex, and Smoking on Electrical Taste Threshold. The Annals of Otology, Rhinology \& Laryngology, 83, 365-369. https://doi.org/10.1177/000348947408300312

[12] Hadfield, J.D. (2010) MCMC Methods for Multi-Response Generalized Linear Mixed Models: The MCMCglmm R Package. Journal of Statistical Software, 33, 1-22. https://doi.org/10.18637/jss.v033.i02

[13] Bates, D., Mächler, M., Bolker, B. and Walker, S. (2015) Fitting Linear Mixed-Effects Models Using Lme4. Journal of Statistical Software, 67, 1-48. https://doi.org/10.18637/jss.v067.i01 
[14] Miersons, M. (1995) Transduction of Taste Stimuli by Receptor Cells in the Gustatory System. In: Doty, R., Ed., Handbook of Olfaction and Gustation, Mercel Dekker, New York, 597-610.

[15] Lobb, B., Elliffe, D.M. and Stillman, J.A. (2000) Reliability of Electrogustometry for the Estimation of Taste Thresholds. Clinical Otolaryngology and Allied Sciences, 25, 531-534. https://doi.org/10.1046/j.1365-2273.2000.00392.x

[16] Stillman, J.A., Morton, R.P. and Goldsmith, D. (2000) Automated Electrogustometry: A New Paradigm for the Estimation of Taste Detection Thresholds. Clinical Otolaryngology and Allied Sciences, 25, 120-125. https://doi.org/10.1046/j.1365-2273.2000.00328.x

[17] Matsuo, R. (2000) Role of Saliva in the Maintenance of Taste Sensitivity. Critical Reviews in Oral Biology \& Medicine, 11, 216-229. https://doi.org/10.1177/10454411000110020501

[18] Al'absi, M., Nakajima, M., Hooker, S., Wittmers, L. and Cragin, T. (2012) Exposure to Acute Stress Is Associated with Attenuated Sweet Taste. Psychophysiology, 49, 96-103. https://doi.org/10.1111/j.1469-8986.2011.01289.x

[19] Maliphol, A.B., Garth, D.J. and Medler, K.F. (2013) Diet-Induced Obesity Reduces the Responsiveness of the Peripheral Taste Receptor Cells. PLoS ONE, 8, e79403. https://doi.org/10.1371/journal.pone.0079403

[20] Yamamoto, T., Nagai, T., Shimura, T. and Yasoshima, Y. (1998) Roles of Chemical Mediators in the Taste System. The Japanese Journal of Pharmacology, 76, 325-348. https://doi.org/10.1254/jip.76.325

[21] Kusano-Tsunoh, A., Nakatsuka, H., Satoh, H., Shimizu, H., Sato, S., Ito, I., Fukao, A. and Hisamichi, S. (2001) Effects of Family-Togetherness on the Food Selection by Primary and Junior High School Students: Family-Togetherness Means Better Food. The Tohoku Journal of Experimental Medicine, 194, 121-127. https://doi.org/10.1620/tjem.194.121

[22] De Castro, J.M., Brewer, E.M., Elmore, D.K. and Orozco, S. (1990) Social Facilitation of the Spontaneous Meal Size of Humans Occurs Regardless of Time, Place, Alcohol or Snacks. Appetite, 15, 89-101. https://doi.org/10.1016/0195-6663(90)90042-7

[23] Lumeng, J.C. and Hillman, K.H. (2007) Eating in Larger Groups Increases Food Consumption. Archives of Disease in Childhood, 92, 384-387. https://doi.org/10.1136/adc.2006.103259

[24] Herman, C.P., Roth, D.A. and Polivy, J. (2003) Effects of the Presence of Others on Food Intake: A Normative Interpretation. Psychological Bulletin, 129, 873-886. https://doi.org/10.1037/0033-2909.129.6.873

[25] Berge, J.M. (2009) A Review of Familial Correlates of Child and Adolescent Obesity: What Has the 21st Century Taught Us So Far? International Journal of Adolescent Medicine and Health, 21, 457-483.

[26] Hammons, A.J. and Fiese, B.H. (2011) Is Frequency of Shared Family Meals Related to the Nutritional Health of Children and Adolescents? Pediatrics, 127, e1565-e1574. https://doi.org/10.1542/peds.2010-1440 